Doi: http://dx.doi.org/10.5212/OlharProfr.v.12i2.287308

\title{
FORMAÇÃO DE PROFESSORES DAS SÉRIES INICIAIS: ALGUMAS CONSIDERAÇÕES SOBRE A FORMAÇÃO MATEMÁTICA E A FORMAÇÃO DOS PROFESSORES DAS LICENCIATURAS EM PEDAGOGIA
}

\section{THE EDUCATION OF EARLY STAGES MATHE- MATICS TEACHERS: CONSIDERATIONS ABOUT THE MATHEMATICAL EDUCATION OF TEA- CHERS IN UNDERGRADUATE COURSES}

\author{
Priscila Mara de Araujo GUALBERTO* \\ Rafael ALMEIDA**
}

\begin{abstract}
Resumo: O presente trabalho teve como objetivos fazer uma análise comparativa dos norteadores dos cursos de Pedagogia, no Brasil, para o ensino de Matemática (Diretrizes Curriculares, Parâmetros Curriculares Nacionais de Matemática e Matrizes de Matemática de quarta série do Ensino Fundamental) e analisar as grades curriculares de sete universidades públicas no estado de São Paulo. A análise dos programas dos cursos de Pedagogia foi realizada a partir da quantificação das horas dedicadas à educação matemática escolar em relação à quantidade total de horas dos cursos, buscando-se verificar se o conteúdo no período de formação prepara suficientemente o professor para desenvolver as habilidades indicadas nos norteadores supracitados. A comparação entre os dois tipos de análises demonstrou que há uma escassez de disciplinas sobre a educação matemática escolar nos cursos de Pedagogia avaliados neste estudo e que o tempo destinado a elas é muito pequeno em relação à duração total do curso, parecendo não ser suficiente para que o professor possa contemplar a matemática escolar em seu caráter sociocultural.
\end{abstract}

\footnotetext{
Doutora em Psicologia pela UFSCAR. E-mail: priscilamagualberto@uol.com.br
}

${ }^{* *}$ Mestre em Educação pela UFSCAR. E-mail: rna.mat@gmail.com 
Formação de professores das séries iniciais: algumas considerações...

Palavras-chave: Matemática Escolar. Currículo de Matemática. Formação de Professores. Séries Iniciais.

Abstract: This comparative study considers the guidelines for the teaching of mathematics in teacher education courses in Brazil, specifically the curriculum guidelines for the fourth grade of elementary school. Furthermore it reviews the curricula of seven public universities in the state of São Paulo. The study considers the number of hours allotted to mathematics education in relation to the total number of hours of the courses, seeking to verify whether the content in their training prepares teachers to teach the required skills. The comparison between the two types of analysis indicated a shortage of courses on mathematics education in Pedagogy courses; furthermore the course load assigned to them is very small when compared to the total number of hours of the course. In other words, the curriculum appears to be inadequate to develop mathematics teachers to fulfill their sociocultural responsibilities

Keywords: School Mathematics. Mathematic's Curriculum. Teacher Formation. Early Series.

\section{INTRODUÇÃO}

Os primeiros cursos de licenciatura foram criados no Brasil na década de trinta, a partir da criação das faculdades de Filosofia, Ciências e Letras. O licenciado dava aulas no ginásio (correspondente, hoje, às séries finais do ensino fundamental) e no colegial (ensino médio). As séries do primário (séries iniciais do ensino fundamental) eram de responsabilidade das normalistas. Desde essa época, portanto, já havia diferenciação na formação do professor que iniciaria a educação matemática escolar com aquele aluno que estava ingressando no Ensino Fundamental.

288 Olhar de professor, Ponta Grossa, 12(2): 287-308, 2009 Disponível em <http://www.uepg.br/olhardeprofessor> 
Focalizando a formação para o ensino de matemática desses professores das séries iniciais, buscou-se avaliar no presente artigo se as disciplinas relacionadas ao ensino de Matemática são suficientes para a sua formação. Essa avaliação foi realizada por meio da investigação dos programas curriculares de alguns cursos de licenciatura em Pedagogia do Estado de São Paulo, incluindo seis universidades públicas estaduais (UNESP campi de Araraquara, Presidente Prudente, Rio Claro e Bauru; USP campus de Ribeirão Preto; e UNICAMP campus de Campinas) e uma federal (Universidade Federal de São Carlos campus de São Carlos), e da análise de alguns norteadores dos cursos de Pedagogia para o ensino de Matemática - Parâmetros Curriculares Nacionais (PCN) de Matemática e Matrizes de Matemática de quarta série do Ensino Fundamental. Foram analisadas as quantidades de horas dedicadas à educação matemática escolar em relação à quantidade total de horas dos cursos e aos norteadores supracitados, buscando-se verificar se essas horas podem suprir todas as exigências do egresso, em referência ao ensino de matemática.

Justifica-se este estudo pela necessidade de se conhecer que tipo de formação em matemática é proposta em grades curriculares de cursos de licenciatura em Pedagogia. O ensino de matemática vem passando por uma série de transformações, devido, entre outros fatores, às mudanças nos meios de observação, de coleção e processamento de dados e, além disso, passou-se a reconhecer que a matemática é afetada pela diversidade cultural. D’Ambrosio (1996, p.59) afirma que “...a matemática é o estilo de pensamento dos dias de hoje, a linguagem adequada para expressar as reflexões sobre a natureza e as maneiras de explicação". Movimentos surgidos na década de 80 - etnomatemática, educação matemática crítica, educação matemática e sociedade - têm investigado e discutido as dimensões políticas e socioculturais da matemática e da educação matemática. (apud MIGUEL, 2005).

Seguindo essa tendência, a educação matemática escolar procura entender as práticas educativas escolares em matemática como processos dinâmicos, criativos, produtivos, originais, condicionados a conjuntos de normas (nem sempre identificáveis) provindas de diferentes instituições sociais além da escola. A cultura matemática passa a ser vista, então, como um sistema normativo e público de signos produzidos através da atividade matemática realizada por diferentes comunidades de práticas além daquela dos matemáticos profissionais. (MIGUEL, 2005). 
Formação de professores das séries iniciais: algumas considerações...

Apesar dessas transformações, que tentam tornar a educação matemática escolar mais próxima do cotidiano do aluno, nos dias de hoje o ensino de matemática ainda continua gerando uma sensação de insatisfação em um grande número de pessoas, sensação resultante dos fracassos obtidos, com frequência, em relação a sua aprendizagem. Essa realidade demonstra que as transformações na ciência Matemática e na educação matemática ainda não chegaram de forma consistente às salas de aula. (BRASIL, 2000).

Mas como mudar uma realidade que parece imutável? Diversos estudos têm sido realizados na busca dessas mudanças. Em um deles, Miguel (2005, p.148) sugere um novo propósito para a educação matemática escolar, com o objetivo de constituir um conjunto de saberes capaz de subsidiar uma avaliação qualitativa profunda do que ocorre nas salas de aula:

[...] as resistências dos estudantes ao processo de apropriação da cultura matemática; as dificuldades apresentadas pelos professores no processo de recepção, ressignificação e transmissão da cultura matemática; a artificialidade das práticas escolares que envolvem a matemática; a natureza algorítmica e pouco significativa da educação matemática escolar, etc.

A prática educativa escolar de matemática deveria ser analisada de modo a considerar os diferentes contextos geopolíticos e institucionais nos quais ela foi criada, sendo a escola participante fundamental dessa criação. Uma análise profunda das práticas sociais envolvidas no ensino de matemática poderia embasar as tão sonhadas mudanças nos currículos de educação matemática escolar, não só nas licenciaturas em Matemática, mas também nas licenciaturas em Pedagogia, curso de formação dos professores das séries iniciais.

Nosso trabalho não tem a pretensão de fazer uma análise tão aprofundada como a que realmente é necessária, mas pretendemos realizar uma pequena contribuição, buscando compreender, ao menos parcialmente, as dificuldades existentes na educação matemática escolar. Como consideramos que as dificuldades referentes à aprendizagem matemática iniciam-se logo nos primeiros anos escolares, focalizaremos nossas investigações nas séries iniciais do Ensino Fundamental.

Se nas licenciaturas em Matemática há tantos problemas (como a artificialidade das práticas pedagógicas, o desinteresse dos alunos 
pela matéria, a dificuldade dos professores em motivar seus alunos para a aprendizagem da matemática, entre outros) a serem solucionados no sentido de tornar a educação matemática escolar mais eficaz no ensino fundamental e médio, a situação parece agravar-se quando se fala do ensino de matemática nas séries iniciais. Nessa fase, em que o grande entrave parece ser a alfabetização das crianças, a matemática acaba sendo colocada em segundo plano, o que prejudica a formação do aluno nos demais anos escolares.

Nos Parâmetros Curriculares de Matemática (BRASIL, 2000, p.15), logo no início das reflexões sobre o ensino de matemática, apresenta-se a importância de sua aprendizagem para a formação geral do indivíduo:

[...] a Matemática desempenha papel decisivo, pois permite resolver problemas da vida cotidiana, tem muitas aplicações no mundo do trabalho e funciona como instrumento essencial para a construção de conhecimentos em outras áreas curriculares. Do mesmo modo, interfere fortemente na formação de capacidades intelectuais, na estruturação do pensamento e na agilização do raciocínio dedutivo do aluno.

Esse já é um argumento forte para a priorização do ensino de matemática desde o início da escolarização. Além disso, apesar do caráter abstrato da Matemática, a origem de seus conceitos e resultados está no mundo real, encontrando aplicações em outras ciências, como Física, Química, Astronomia, etc., e em inúmeros aspectos práticos da vida cotidiana. Mesmo outras áreas do conhecimento, como Economia, Psicologia, Sociologia, Política, Medicina, são favorecidas pela Matemática, pois o raciocínio lógico que ela permite desenvolver no indivíduo constitui subsídio importante em função de conceitos, linguagens, relações, atitudes, etc. (BRASIL, 2000).

Vê-se, portanto, que não proporcionar, na escola, desde o início da escolarização, oportunidades efetivas de aprendizagem matemática significa, em última análise, restringir o campo de conhecimento do indivíduo e limitar suas potencialidades como estudante e como cidadão. Franco e Sztajn (1999) consideram que a educação matemática escolar tem o dever de preparar o aluno para participar de processos democráticos, sendo necessário, para isso, que o professor fundamente seu ensino em problemas sociais reais, promovendo o 
Formação de professores das séries iniciais: algumas considerações...

pensamento crítico ao proporcionar ao aluno a análise de problemas verdadeiramente encontrados no contexto de uma sociedade multicultural como a nossa.

Levantada a importância da educação matemática escolar já nas séries iniciais, podemos nos perguntar: estão os professores das séries iniciais aptos para ensinar matemática? Os cursos de formação de professores das séries iniciais dão conta de capacitar esses professores adequadamente?

Percebemos que essas são questões bastante complexas e neste trabalho não almejaremos respondê-las; contudo, buscaremos levantar indagações sobre o conhecimento matemático do professor das séries iniciais. Para isso, procedemos uma investigação que se pautou em analisar o que os documentos oficiais (Parâmetros Curriculares Nacionais e Matrizes de Matemática) e as Diretrizes Curriculares dos Cursos de Pedagogia salientam como elementar para o ensino de matemática nas séries iniciais do Ensino Fundamental e também analisar nos documentos dos Cursos de Pedagogia de sete universidades públicas do estado de São Paulo (Ementas e Grades Curriculares) qual a carga horária prevista para a formação do professor em educação matemática escolar. Esses documentos são relevantes, pois traçam o perfil da formação do licenciado em Pedagogia bem como o perfil do professor de matemática das séries iniciais.

Este artigo está composto por quatro partes. Inicialmente, apresentamos os documentos que indicam as responsabilidades legais do professor das séries inicias, bem como as diretrizes curriculares do curso de Pedagogia. Em seguida, expomos uma pesquisa que evidencia o tempo destinado ao estudo do ensino da matemática das séries iniciais. Na sequência, buscamos estabelecer uma reflexão entre o que é apresentado nos documentos oficiais e o que foi encontrado na pesquisa on-line nos cursos de Pedagogia de algumas universidades públicas do estado de São Paulo. Por fim, são apresentadas algumas reflexões no intuito de levantar algumas indagações sobre a formação matemática dos alunos dos cursos de Licenciatura em Pedagogia.

\section{MÉTODO}

Inicialmente, foram coletadas nas Diretrizes do Curso de Pedagogia e nos Parâmetros Curriculares Nacionais de Matemática as informações sobre a formação do professor das séries iniciais para 
o ensino de Matemática. Em seguida, como parte dessa análise dos documentos oficiais, foi elaborado um quadro comparativo entre essas informações e as Matrizes de Matemática para a quarta série do Ensino Fundamental, a fim de analisar o que se espera que um aluno de quarta série tenha aprendido sobre matemática.

Posteriormente, foram coletados, por meio virtual, os programas e ementas dos cursos de Pedagogia (presenciais) de sete universidades públicas paulistas (UNESP campi de Araraquara, Presidente Prudente, Rio Claro e Bauru; USP campus de Ribeirão Preto; UNICAMP campus de Campinas; e UFSCar campus de São Carlos). Foram realizadas buscas on-line sobre os programas e as ementas dos cursos e os dados coletados foram analisados com relação à quantidade de disciplinas que abordam a matemática e o tempo destinado às mesmas.

\section{FORMAÇÃO DO PROFESSOR PARA EDUCAÇÃO MATEMÁTICA ESCOLAR NAS SÉRIES INICIAIS}

Nos programas curriculares a matemática tem um papel de destaque, pois é entendida como "a fonte mais segura do conhecimento humano, sua pedra de toque" (ERNEST, 1994). Mas, para muita gente, a matemática é considerada um mistério. Segundo Matos (2005), foi oferecido à matemática um papel de juiz que decide quem está apto ou não na sociedade e, devido a isso, ela seria uma forma de acesso aos processos de decisão da sociedade.

No entanto, ao verificarmos o rendimento dos alunos, percebemos uma grande dificuldade deles com a matemática. Quais seriam as causas desse fenômeno? As razões são diversas e vários pesquisadores têm se debruçado durante anos sobre essa questão. Paola Sztajn (2002) fez uma revisão da literatura dos anos 90 sobre o foco o que necessita saber um professor de matemática. Pautandose em Shulman (1987), a autora apresenta três categorias de saber: disciplinar, pedagógico-disciplinar e curricular.

O conhecimento disciplinar seria o conhecimento do conteúdo a ser ensinado. O pedagógico-disciplinar seria a ligação entre a pesquisa sobre ensino e a pesquisa sobre aprendizagem. E o conhecimento curricular seria "o amálgama especial entre o conteúdo e a pedagogia" (SHULMAN, 1987, p. 19). Shulman (1987, p. 19) afirma que, para se ensinar uma disciplina, o professor deve, primeiramente,

[...] compreendê-la de diversos modos, a partir de diferentes pers- 
Formação de professores das séries iniciais: algumas considerações...

pectivas, estabelecendo relações entre os vários tópicos e entre a sua disciplina e as demais. O professor, entretanto, deve ser capaz de transformar esse seu conhecimento em algo pedagogicamente útil e adaptável aos diversos níveis de habilidade, conhecimento e formação de seus alunos.

Portanto, não basta conhecer os conteúdos para poder ensinálos, são necessários outros conhecimentos. Sztajn (2002, p.21) afirma que "o conhecimento que alguém tem da matemática envolve o que se sabe sobre o assunto, o que sabe sobre a organização do campo e suas atitudes perante o assunto". Nessa mesma perspectiva, Mizukami (2004) coloca que o conhecimento do conteúdo é necessário, mas não suficiente para garantir um ensino efetivo.

As Diretrizes Curriculares Nacionais para o curso de graduação em Pedagogia, licenciatura, instituídas por Resolução do Conselho Nacional de Educação/Conselho Pleno - Resolução CNE/CP N ${ }^{\circ} 1$, de 15 de maio de 2006 -, apresentam o pedagogo como um profissional generalista. $\mathrm{O}$ artigo $3^{\circ}$ dessa Resolução salienta a função do pedagogo, indicando que o estudante de Pedagogia trabalhará

[...] com um repertório de informações e habilidades composto por pluralidade de conhecimentos teóricos e práticos, cuja consolidação será proporcionada no exercício da profissão, fundamentando-se em princípios de interdisciplinaridade, contextualização, democratização, pertinência e relevância social, ética e sensibilidade afetiva e estética.

Portanto, a profissão do pedagogo não se restringe ao magistério, mas sua atividade pode ser desempenhada por ele. $\mathrm{O}$ artigo $4^{\circ} \mathrm{da}$ Resolução citada informa as funções do licenciado em Pedagogia:

O curso de Licenciatura em Pedagogia destina-se à formação de professores para exercer funções de magistério na Educação Infantil e nos anos iniciais do Ensino Fundamental, nos cursos de Ensino Médio, na modalidade Normal, de Educação Profissional na área de serviços e apoio escolar e em outras áreas nas quais sejam previstos conhecimentos pedagógicos.

Vimos que ensinar é uma atividade complexa, que depende da aquisição de uma série de habilidades por parte do professor, referen- 
tes tanto ao conteúdo disciplinar quanto à prática pedagógica relacionada a esse conteúdo. Quando se fala sobre o ensino de matemática nas séries iniciais, além das habilidades pedagógicas, é necessário que o professor tenha um conhecimento adequado do conteúdo. Segundo os Parâmetros Curriculares Nacionais de Matemática (BRASIL, 2000), parte dos problemas referentes à educação matemática escolar relaciona-se ao processo de formação do professor, tanto a formação inicial quanto a continuada, ficando o professor à mercê de livros didáticos que, muitas vezes, são de baixa qualidade.

O Quadro 1 compara o que as Diretrizes Curriculares consideram que o profissional da Pedagogia deve ser capaz ao final do curso com os PCN's de Matemática mais a Matriz de Matemática, que indica os conhecimentos que o aluno da quarta série do Ensino Fundamental deve apresentar ao final do ano letivo. Podemos verificar que se exige que o pedagogo seja um profissional capaz de compreender o contexto sociocultural em que seus alunos estão inseridos e, com base nisso, agir de acordo com a realidade do aluno, seja na gestão, na coordenação ou no magistério. Vemos essa ideia bem definida quando, no art. $5^{\circ}$ da Resolução que institui as Diretrizes Curriculares do curso de Pedagogia (Resolução $\mathrm{CNE} / \mathrm{CP} \mathrm{N}^{\circ} 1$, de 2006), se afirma que o egresso do curso de Pedagogia deverá ter desenvolvido, dentre outras, as seguintes aptidões:

Promover e facilitar relações de cooperação entre a instituição educativa, a família e a comunidade;

Identificar problemas socioculturais e educacionais com postura investigativa, integrativa e propositiva em face de realidades complexas, com vistas a contribuir para superação de exclusões sociais, étnico-raciais, econômicas, culturais, religiosas, políticas e outras;

Realizar pesquisas que proporcionem conhecimentos, entre outros: sobre alunos e alunas e a realidade sociocultural em que estes desenvolvem suas experiências não-escolares; sobre processos de ensinar e de aprender, em diferentes meios ambiental-ecológicos; sobre propostas curriculares; e sobre organização do trabalho educativo e práticas pedagógicas.

Além disso, podemos observar que os PCN's orientam que o professor tenha um entendimento abrangente da Matemática, con- 
Formação de professores das séries iniciais: algumas considerações...

siderando suas características, métodos, ramificações e aplicações, sem contar o conhecimento que se espera que ele tenha sobre as vivências de aprendizagem de seus alunos e sobre objetivos e conteúdos de ensino.

(Continua)

\begin{tabular}{|c|c|c|c|}
\hline $\begin{array}{l}\text { DIRETRIZES CURRICULARES } \\
\text { DO CURSO DE PEDAGOGIA }\end{array}$ & $\begin{array}{l}\text { PCN DE MA- } \\
\text { TEMÁTICA }\end{array}$ & \multirow{2}{*}{\multicolumn{2}{|c|}{$\begin{array}{l}\text { MATRIZ DE MATEMÁTICA DE } \\
4^{\text {a }} \text { SÉRIE - ENSINO FUNDAMENTAL } \\
\text { Ao concluir a } 4^{\text {a }} \text { Série do Ensino Fun- } \\
\text { damental, o aluno deve conseguir: }\end{array}$}} \\
\hline $\begin{array}{c}\text { Aptidões que deverá ter desen- } \\
\text { volvido o egresso do curso de } \\
\text { Pedagogia: }\end{array}$ & $\begin{array}{l}\text { Numa reflexão } \\
\text { sobre o ensino } \\
\text { da Matemá- } \\
\text { tica, é de } \\
\text { fundamental } \\
\text { importância ao } \\
\text { professor: }\end{array}$ & & \\
\hline $\begin{array}{c}\text { Atuar com ética e compromisso } \\
\text { com vistas à construção de } \\
\text { uma sociedade justa, equânime, } \\
\text { igualitária. }\end{array}$ & $\begin{array}{c}\text { Identificar } \\
\text { as principais } \\
\text { características } \\
\text { dessa ciência, } \\
\text { de seus méto- } \\
\text { dos, de suas } \\
\text { ramificações e } \\
\text { aplicações. }\end{array}$ & & $\begin{array}{l}\text { Identificar a locali- } \\
\text { zação /movimen- } \\
\text { tação de objeto, } \\
\text { em mapas, croquis } \\
\text { e outras represen- } \\
\text { tações gráficas. }\end{array}$ \\
\hline $\begin{array}{l}\text { Compreender, cuidar e educar } \\
\text { crianças de zero a cinco anos, } \\
\text { de forma a contribuir } \\
\text { para o seu desenvolvimento nas } \\
\text { dimensões, entre outras, física, } \\
\text { psicológica, intelectual, social. }\end{array}$ & $\begin{array}{l}\text { Conhecer } \\
\text { a história } \\
\text { de vida dos } \\
\text { alunos, sua } \\
\text { vivência de } \\
\text { aprendizagens } \\
\text { fundamentais, } \\
\text { seus conheci- } \\
\text { mentos infor- } \\
\text { mais sobre um } \\
\text { dado assunto, } \\
\text { suas condições } \\
\text { sociológicas, } \\
\text { psicológicas e } \\
\text { culturais. }\end{array}$ & $\begin{array}{l}\text { DESCRITORES } \\
\text { TEMA } 1 \\
\text { ESPAÇO E } \\
\text { FORMA }\end{array}$ & $\begin{array}{c}\text { Identificar pro- } \\
\text { priedades comuns } \\
\text { e diferenças entre } \\
\text { poliedros e corpos } \\
\text { redondos, rela- } \\
\text { cionando figuras } \\
\text { tridimensionais } \\
\text { com suas planifi- } \\
\text { cações. }\end{array}$ \\
\hline
\end{tabular}




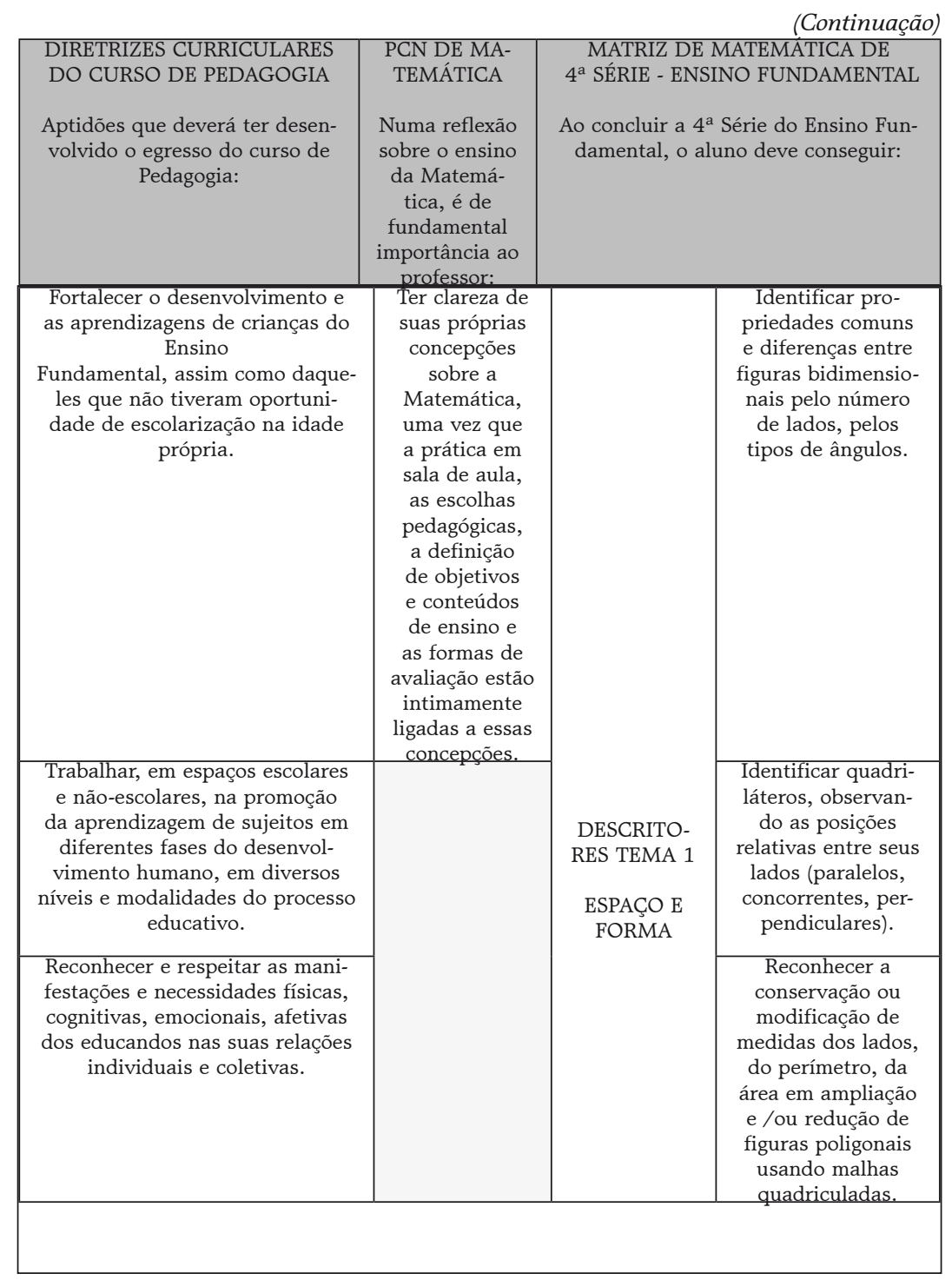

Olhar de professor, Ponta Grossa, 12(2): 287-308, 2009 
(Continuação)

\begin{tabular}{|c|c|c|}
\hline DIRETRIZES CURRICULARES & $\begin{array}{l}\text { PCN DE MA- } \\
\text { TEMÁTICA }\end{array}$ & $\begin{array}{c}\text { MATRIZ DE MATEMÁTICA DE } \\
4^{\mathrm{a}} \text { SÉRIE - ENSINO FUNDAMENTAL }\end{array}$ \\
\hline $\begin{array}{c}\text { Aptidões que deverá ter desen- } \\
\text { volvido o egresso do curso de } \\
\text { Pedagogia: }\end{array}$ & $\begin{array}{l}\text { Numa reflexão } \\
\text { sobre o ensino } \\
\text { da Matemá- } \\
\text { tica, é de } \\
\text { fundamental } \\
\text { importância ao } \\
\text { professor: }\end{array}$ & $\begin{array}{l}\text { Ao concluir a } 4^{\text {a }} \text { Série do Ensino Fun- } \\
\text { damental, o aluno deve conseguir: }\end{array}$ \\
\hline
\end{tabular}

\begin{tabular}{|c|c|c|}
\hline $\begin{array}{c}\text { Ensinar Língua Portuguesa, } \\
\text { Matemática, Ciências, História, } \\
\text { Geografia, Artes, } \\
\text { Educação Física, de forma } \\
\text { interdisciplinar e adequada às } \\
\text { diferentes fases do desenvolvi- } \\
\text { mento humano. }\end{array}$ & \multirow{4}{*}{$\begin{array}{l}\text { DESCRITORES } \\
\text { TEMA } 2 \\
\text { GRANDEZAS E } \\
\text { MEDIDAS }\end{array}$} & $\begin{array}{l}\text { Estimar a medida } \\
\text { de grandezas utili- } \\
\text { zando unidades de } \\
\text { medida convencio- } \\
\text { nais ou não. }\end{array}$ \\
\hline $\begin{array}{l}\text { Relacionar as linguagens dos } \\
\text { meios de comunicação à edu- } \\
\text { cação, nos processos didático- } \\
\text { pedagógicos, demonstrando } \\
\text { domínio das tecnologias de } \\
\text { informação e comunicação ade- } \\
\text { quadas ao desenvolvimento de } \\
\text { aprendizagens significativas. }\end{array}$ & & $\begin{array}{c}\text { Resolver problemas } \\
\text { significativos utili- } \\
\text { zando unidades de } \\
\text { medida padroniza- } \\
\text { das como } \mathrm{Km} / \mathrm{m} / \\
\mathrm{cm} / \mathrm{mm}, \mathrm{Kg} / \mathrm{g} / \\
\mathrm{mg}, \mathrm{l} / \mathrm{ml} .\end{array}$ \\
\hline $\begin{array}{c}\text { Promover e facilitar relações de } \\
\text { cooperação entre a instituição } \\
\text { educativa, a família e a comu- } \\
\text { nidade. }\end{array}$ & & $\begin{array}{l}\text { Estabelecer rela- } \\
\text { ções entre unida- } \\
\text { des de tempo. }\end{array}$ \\
\hline $\begin{array}{c}\text { Identificar problemas socio- } \\
\text { culturais e educacionais com } \\
\text { postura investigativa, integrati- } \\
\text { va e propositiva em face de re- } \\
\text { alidades complexas, com vistas } \\
\text { a contribuir para superação de } \\
\text { exclusões sociais, étnico-raciais, } \\
\text { econômicas, culturais, religio- } \\
\text { sas, políticas e outras. }\end{array}$ & & $\begin{array}{l}\text { Estabelecer } \\
\text { relações entre o } \\
\text { horário de início e } \\
\text { término e/ou in- } \\
\text { tervalo da duração } \\
\text { de um evento ou } \\
\text { acontecimento. }\end{array}$ \\
\hline $\begin{array}{l}\text { Demonstrar consciência da } \\
\text { diversidade, respeitando as di- } \\
\text { ferenças de natureza ambiental- } \\
\text { ecológica, étnico-racial, de } \\
\text { gêneros, faixas geracionais, } \\
\text { classes sociais, religiões, } \\
\text { necessidades especiais, escolhas } \\
\text { sexuais, entre outras. }\end{array}$ & $\begin{array}{l}\text { TEMA } 2 \\
\text { (continuação) } \\
\text { GRANDEZAS E } \\
\text { MEDIDAS }\end{array}$ & $\begin{array}{l}\text { Em um problema, } \\
\text { estabelecer trocas } \\
\text { entre cédulas e } \\
\text { moedas do sistema } \\
\text { monetário brasilei- } \\
\text { ro, em função de } \\
\text { seus valores. }\end{array}$ \\
\hline
\end{tabular}


(Continuação)

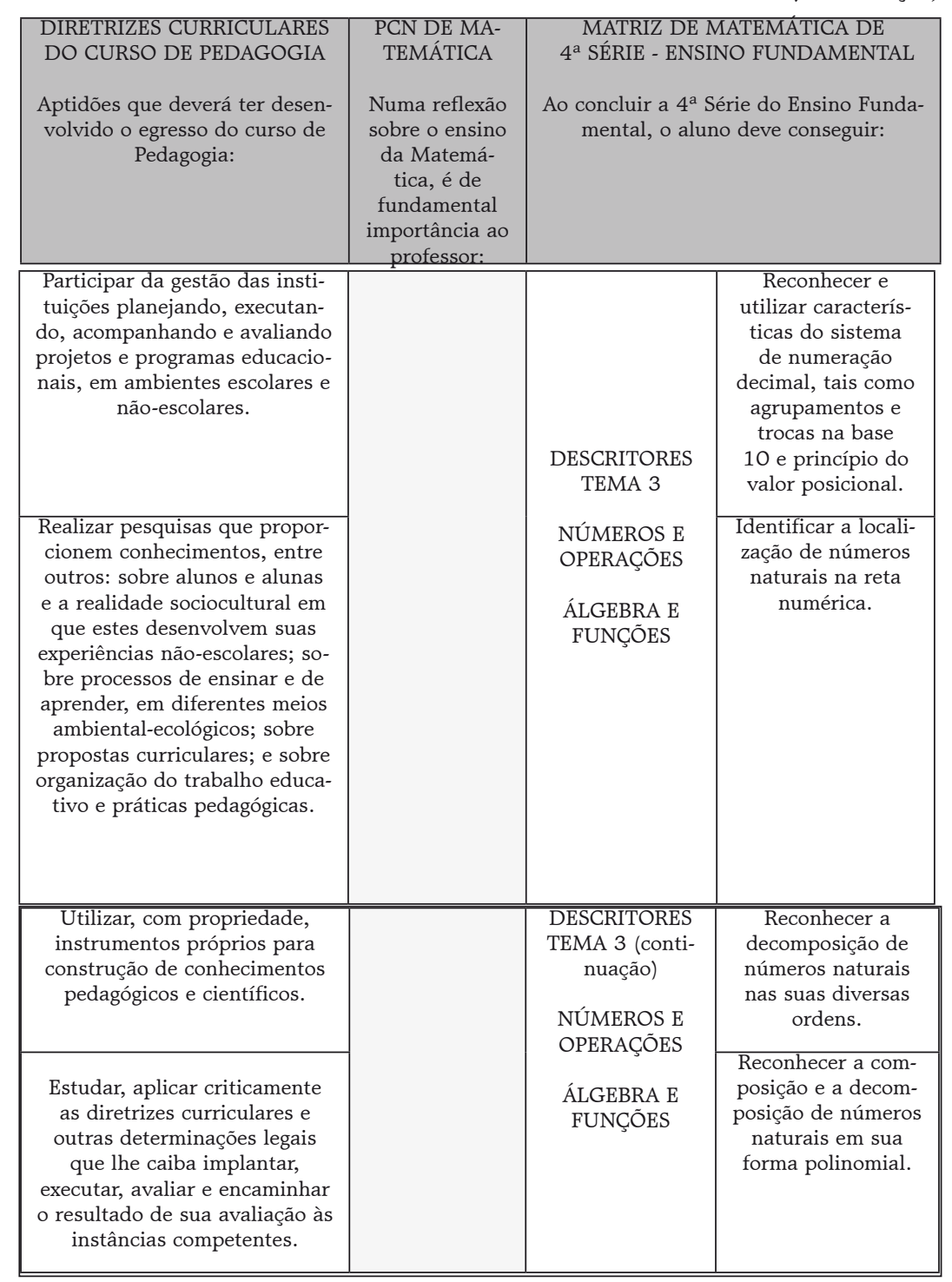

Olhar de professor, Ponta Grossa, 12(2): 287-308, 2009. 
(Continuação)

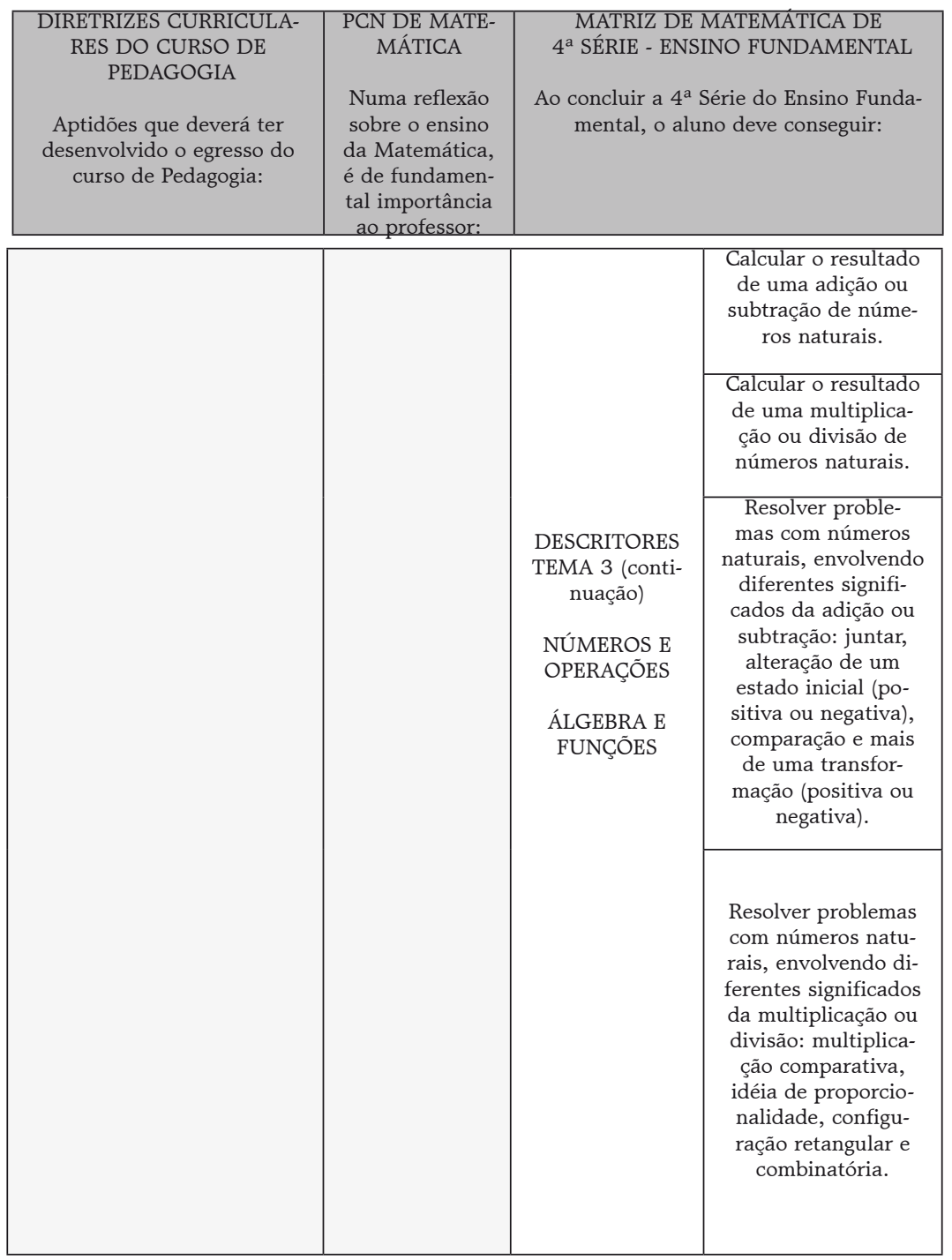


Priscila Mara de Araujo GUALBERTO; Rafael ALMEIDA

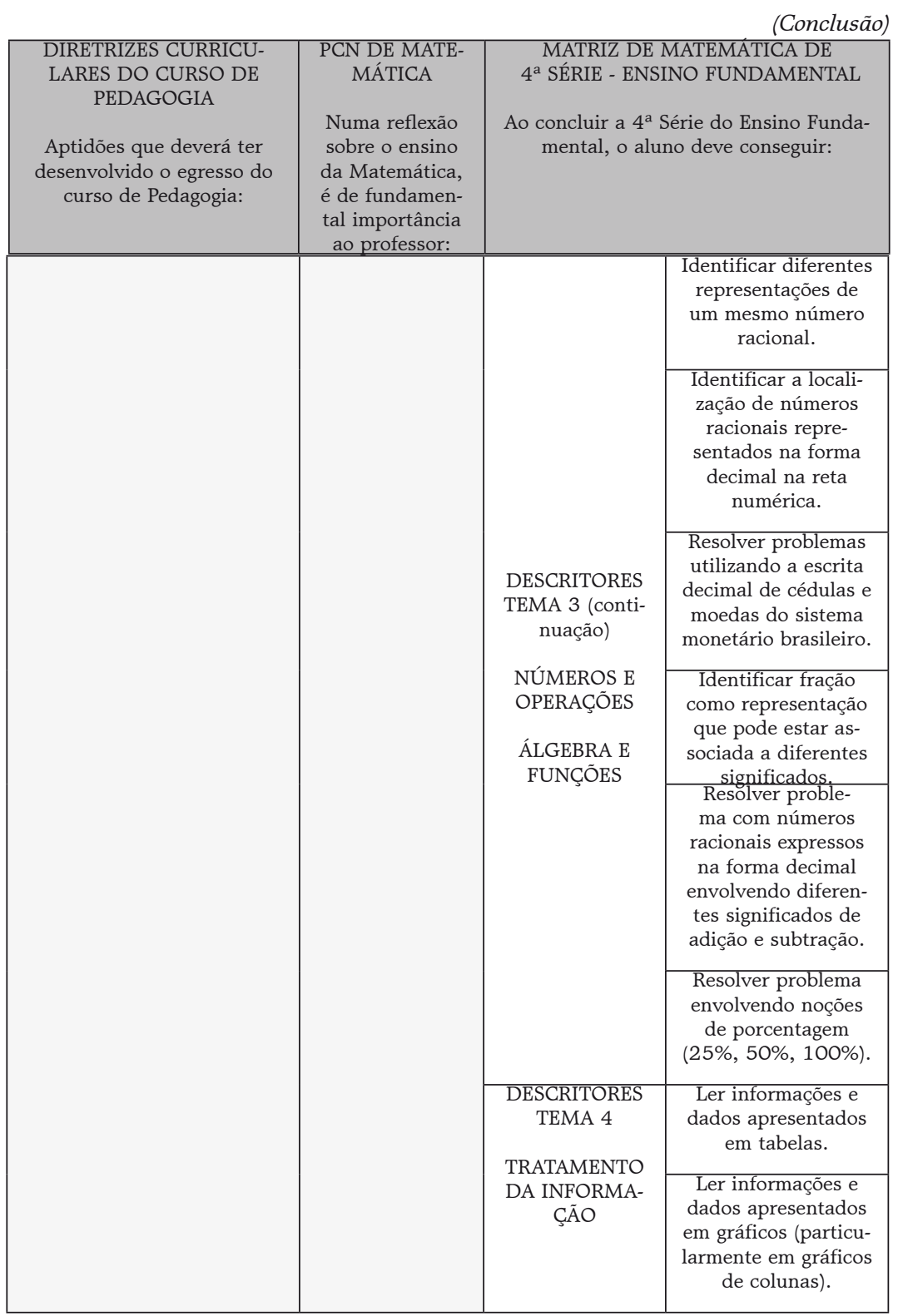

Quadro 1 - Principais norteadores do licenciado em Pedagogia em relação à formação generalista (Diretrizes Curriculares) e ao ensino de Matemática (PCN de Matemática e Matrizes de Matemática de quarta série do Ensino Fundamental).

Olhar de professor, Ponta Grossa, 12(2): 287-308, 2009

Disponível em <http://www.uepg.br/olhardeprofessor > 
Formação de professores das séries iniciais: algumas considerações...

Teoricamente, o curso de licenciatura em Pedagogia, orientado por essas Diretrizes Curriculares, formará um professor capaz de seguir as orientações dos PCN's e, dessa forma, um professor capaz de fazer com que seus alunos, ao final da quarta série, demonstrem os conhecimentos indicados na Matriz de Matemática, relacionados aos descritores Espaço e Forma, Grandezas e Medidas, Número e Operações, Álgebra e Funções e Tratamento da Informação.

Entendemos que as diretrizes curriculares do curso de Pedagogia apontam para a formação de um profissional polivalente que, além de ensinar Matemática, Língua Portuguesa, Ciências, História, Geografia, Artes, Educação Física, deve, também, ter uma atuação extraclasse, como pode ser constatado no Quadro 1, por exemplo, quando se diz que o professor deverá "promover e facilitar relações de cooperação entre a instituição educativa, a família e a comunidade", ou que o professor deverá "trabalhar, em espaços escolares e não-escolares, na promoção da aprendizagem de sujeitos em diferentes fases do desenvolvimento humano, em diversos níveis e modalidades do processo educativo".

As considerações sobre a formação do professor contidas nas Diretrizes Curriculares (Quadro 1) são generalistas e não específicas e, dessa forma, não é possível relacioná-las diretamente aos conteúdos da Matriz de Matemática da quarta-série. Os descritores da matriz trazem informações restritas sobre o que o aluno deverá ser capaz de realizar ao final de um ciclo educacional, como, por exemplo, quando se diz, no Descritor Tema 1 (Espaço e Forma), que o aluno deverá estar apto a "identificar propriedades comuns e diferenças entre figuras bidimensionais pelo número de lados, pelos tipos de ângulos"; ou, no Tema 4 (Tratamento da informação), que o aluno deverá conseguir "Ler informações e dados apresentados em tabelas". Observa-se, portanto, a dificuldade em estabelecer vinculações particulares entre esses dois textos norteadores da formação do professor das séries iniciais do Ensino Fundamental.

O licenciado em Pedagogia, cuja atuação profissional é multifacetada e ampla, deve ser também, de acordo com as Diretrizes Curriculares, um professor de matemática nos primeiros anos do Ensino Básico. Nos PCN's de Matemática ressalta-se que o professor de matemática deve ter clareza de suas próprias concepções sobre a Matemática, como se pode observar no Quadro 1, bem como identificar as principais características dessa ciência e trabalhar conteúdos inerentes a ela até o quinto ano do ensino fundamental. 
De acordo com Lanner de Moura e Sousa (2008, p. 64), “um número razoável de alunos que buscam o curso de Pedagogia o fazem para não enfrentar, num curso superior, as mesmas dificuldades que tiveram com a matemática".

Muitos alunos do curso de pedagogia optam por esse curso para evitarem a matemática, principalmente a álgebra. Diante disso, fica clara a contradição em um curso que pretende formar professores de matemática, mas, além de apresentar uma formação tão ampla e generalista, recebe alunos que, em número significativo, buscam evitar a matemática.

Vamos verificar, agora, como se dá a formação matemática dos professores das séries iniciais em algumas universidades e avaliar se, na prática, eles estão preparados para cumprir com todos os norteadores apresentados no Quadro 1.

\section{ANÁLISE DOS PROGRAMAS}

A análise demonstrou que há uma escassez de disciplinas sobre a questão da matemática nos cursos de Pedagogia. Em todas as universidades pesquisadas, apenas uma disciplina trata sobre o tema "ensino de matemática", com algumas variações de nomes: Metodologia do Ensino de Matemática; Metodologia do Ensino das Séries Iniciais do Ensino Fundamental - Matemática; Fundamentos do Ensino de Matemática; e Metodologia e Prática de Ensino de Matemática: Teoria e Prática. As cargas horárias dessas disciplinas são descritas a seguir. Considerou-se o total de horas das disciplinas relacionadas ao ensino de Matemática, sem preocupações com diferentes nomes de disciplinas.

Na UNICAMP, o curso possui uma disciplina com $60 \mathrm{~h}$, num total de 2.850 horas de curso. Na USP, no programa do curso também há somente uma disciplina de $60 \mathrm{~h}$, com o curso totalizando 2.800 horas. Nos campi da UNESP, tem-se uma disciplina de $120 \mathrm{~h}$ com uma carga horária total do curso de 3.330 horas. E na UFSCar, uma disciplina de 90 h num curso com 3.320 horas. Em geral o tempo destinado ao estudo de matemática e metodologia matemática fica entre $2,1 \%$ e 3,6 \% do tempo total destinado ao curso. Diante disso, concluímos que o tempo destinado ao estudo dos conteúdos matemáticos e dos conhecimentos pedagógicos desses conteúdos é pequeno diante da carga horária total do curso de Pedagogia. Entretanto, não 
Formação de professores das séries iniciais: algumas considerações...

podemos afirmar que o tempo escasso necessariamente leva a uma má formação matemática do professor das séries inicias. Para isso, faz-se necessária a realização de novas investigações.

A pergunta que se faz é esta: será que os cursos de formação de professores das séries iniciais, com essa ampla formação, conseguem contemplar os conhecimentos específicos de matemática $\square$ conhecimentos de conteúdo e conhecimento pedagógico do conteúdo $\square$ que um professor deve desenvolver? Para tentar responder a essa pergunta é necessário que os cientistas da educação e da educação matemática preocupem-se mais com as dificuldades que grande parte dos alunos e dos próprios professores vem sentindo em uma área que se apresenta, ainda, tão carente de estudos $\square$ a do ensino da matemática nas séries iniciais. Consideramos que, no cenário atual, é difícil responder a qualquer uma das questões levantadas no presente artigo.

\section{CONSIDERAÇÕES FINAIS}

O problema entre a formação inicial e a prática docente da educação matemática escolar tem sido foco de investigações nas licenciaturas em Matemática. Contudo, nas licenciaturas em Pedagogia, nas quais, como vimos, nem os conteúdos nem as disciplinas metodológicas de ensino de matemática parecem ser suficientes para preparar o professor para introduzir os conceitos matemáticos nas séries iniciais, essa discussão ainda não tomou as devidas proporções.

Embora as crianças comecem a elaborar desde cedo as idéias que irão desenvolver até a formação do conceito de número natural, as discussões sobre os processos de aquisição dos conceitos relativos às quatro operações com números naturais têm sido desconsideradas pelos cursos de licenciatura em Matemática, que acreditam ser essa uma preocupação dos cursos de formação de professores das séries iniciais. Moreira e David (2005, p.52) afirmam:

[...] acreditamos que a separação acentuada existente entre a formação do docente desse ciclo e a do professor que leciona nos outros ciclos do ensino básico é equivocada, pois pode contribuir para intensificar a descontinuidade do processo de transição das séries iniciais para a quinta série e seguintes.

As dificuldades com a matemática ultrapassam as séries iniciais e, com frequência, manifestam-se até o final do ensino fundamental. 
O trabalho com as operações aritméticas básicas, muitas vezes menosprezadas pelos cursos de licenciatura em matemática, é considerado instrumento de apoio no processo de construção do próprio conceito abstrato de número. O professor, sobretudo o das séries iniciais, precisa incentivar um processo de construção de significados por meio de "concretizações" em diferentes situações, em detrimento de definições de propriedades estruturais das operações. (MOREIRA \& DAVID, 2005).

Entender essas operações aritméticas significa compreender a organização lógico-formal-dedutiva da matemática escolar; sem essa compreensão, a matemática torna-se um amontoado de fatos dispersos, sem conexão. Compreender essa organização facilita o entendimento de como as teorias estão estruturadas, possibilitando ao aluno tirar suas próprias conclusões e adaptá-las a sua realidade, tomando a matemática como mais uma possibilidade de expressão de sua subjetividade. (FONSECA, 1999).

A importância dos números e das operações aritméticas é levantada nos descritores da Matemática para a educação básica e apresentada como o "tema de maior prioridade para a Matemática ensinada na educação básica" (Descritores Tema 3, no Quadro 1). Isso indica que até a quarta série do Ensino Fundamental a criança deve aprender o significado dos números, partindo de contextos significativos, sendo capaz de resolver situações-problema que impliquem contagem, medidas, significados das operações, leitura e escrita de números naturais e racionais, ordenação dos números, realização de cálculos, por escrito, envolvendo esses números, noções de porcentagem e estratégias de verificação.

As transformações que tem sofrido a Matemática ao longo dos anos alertam-nos para uma maior relevância da educação matemática escolar, no sentido de compreender que os contextos institucionais (escolar e não-escolar) influenciam o aprendizado do aluno e sua motivação para aprender. Esse cenário destitui a matemática escolar de um caráter neutro, fixo, rígido e a considera como parte essencial na formação sócio-cultural e política dos alunos. Fonseca (1999, p. 160) considera que a construção da cidadania, assunto tão discutido atualmente nas teorias educativas,

pede hoje um cuidado crescente com o aspecto sócio-cultural da abordagem matemática e com sua dimensão histórica. Torna-se cada vez mais evidente a necessidade de contextualizar o conhe- 
Formação de professores das séries iniciais: algumas considerações...

cimento matemático a ser transmitido, buscar as suas origens, acompanhar a sua evolução, explicitar a sua finalidade ou o seu papel na interpretação e na transformação da realidade do aluno. (...) Passa-se, então a considerar e a valorizar a matemática como elemento da cultura humana e, por isso, a dedicar-se a ela um espaço próprio na educação escolar, (...) criando condições para que o aluno perceba, experimente, compreenda e consiga, então, transpor com desenvoltura cada ruptura histórica ou desvio de curso importante nessa evolução, por que identificados com a evolução de seu próprio pensamento.

Mas será que o professor das séries iniciais compreende a matemática segundo essa organização lógico-formal-dedutiva? O curso de licenciatura em Pedagogia tem formado um profissional capaz de conferir esse caráter sociocultural à educação matemática escolar? Essas são questões que necessitam de respostas, pois nosso estudo indica que as horas dedicadas à matemática no curso de licenciatura em Pedagogia são poucas e, aparentemente, insuficientes para dar conta desse complexo entendimento.

Pudemos observar, também, que não há relação direta entre os três textos aqui apresentados (Diretrizes Curriculares, Parâmetros Curriculares Nacionais de Matemática e Matrizes da Matemática), que, em tese, devem ter a função de nortear os projetos pedagógicos dos cursos de licenciatura em Pedagogia e serem fundamentadores da formação do professor das séries iniciais do Ensino Fundamental. Torna-se relevante, portanto, que novos estudos busquem propor inter-relações entre esses textos.

Todavia, não devemos ignorar que para solucionar os problemas da educação matemática escolar nas séries iniciais é necessário compreender a realidade dos professores e dos alunos. Compreender a realidade que é vivida no dia-a-dia da escola. Por conseguinte, é necessário que os profissionais da área da educação e da matemática tenham maior interesse pelos processos de ensino-aprendizagem que ocorrem nas séries iniciais do ensino fundamental, pois, na literatura atual, percebemos a falta de estudos que nos permitissem tirar alguma conclusão acerca do problema das dificuldades em matemática apresentadas pelos alunos das séries iniciais.

A investigação realizada baseou-se apenas no que ocorre oficialmente nos cursos, pois os dados foram coletados a partir do que as universidades tornam público em seus sites. Porém, temos consciência 
de que uma análise mais adequada da formação do professor deve envolver outros meios de coleta de dados, como entrevistas com os professores e alunos dos cursos de Pedagogia, a fim de verificar quais conceitos e competências são efetivamente tratados no cotidiano das universidades. Fica, portanto, uma sugestão para futuros estudos.

\section{REFERÊNCIAS}

BRASIL. Secretaria de Educação Fundamental. Parâmetros Curriculares Nacionais:

Matemática. 2. ed. Rio de Janeiro: DPEA, 2000.

BRASIL. Ministério da Educação. Diretrizes Curriculares Nacionais da Pedagogia. Resolução CNE/CP n¹, de 15 de maio de 2006. Disponível em: <www.mec.gov.br.> Acesso em: maio, 2007.

D'AMBROSIO, U. Educação matemática: da teoria à prática. Campinas, SP: Editora Papirus, 1996, p.56-78.

ERNEST, P. The philosophy of mathematics and the didactics of mathematics. In: BIEHLER, R. et al. (Eds.). Didactics of mathematics as a scientific discipline. London: Kluver Academic Publishers, 1994.

FONSECA, M. C. F. Os limites do sentido no ensino de matemática. Educação e Pesquisa, São Paulo, jan./jun. 1999, v. 25, n. 1, p. 147-162.

FRANCO, C.; SZTAJN, P. Educação em ciências e matemática: identidade e implicações para políticas de formação continuada de professores. In: MOREIRA, A. F. B. (Org.). Currículo: políticas e práticas. Campinas, SP: Papirus, 1999, cap. 6.

LANNER DE MOURA, A. R.; SOUSA, M. C. Dando movimento ao pensamento algébrico. Zetetike. 16. n. 30, p. 63-76, 2008.

MATOS, J. F. Matemática, educação e desenvolvimento social - questionando mitos que sustentam opções actuais em desenvolvimento curricular em matemática. Disponível em: <www.educ.fc.ul.pt/docentes/jfmatos/comunicacoes/jfm_seminario_pa. pdf >. Acesso em: maio de 2007.

MIGUEL, A. História, filosofia e sociologia da educação matemática na formação do professor: um programa de pesquisa. Revista Educação e Pesquisa, São Paulo, v. 31, n. 1, p. 137-152, jan./abr. 2005.

MIZUKAMI, M. G. N. Aprendizagem da docência: algumas contribuições de L. S. Shulman. Revista Educação, v. 29, n. 2, 2004. Disponível em: < http:// 
Formação de professores das séries iniciais: algumas considerações...

www.ufsm.br/ce/revista/revce/2004/O2/a3.htm>. Acesso em: abr. 2007.

MOREIRA, P. C.; DAVI, M. M. M. S. O conhecimento matemático do professor: formação e prática docente na escola básica. Revista Brasileira de Educação, Jan/Fev/Mar/Abr 2005, n.28.

SHULMAN, L. S. Knowledge and teaching: foundations of the new reform. Harvard Educational Review, 1987, v. 57, n 1, p. 1-22.

SZTAJN, P. O que precisa saber um professor de matemática? Uma revisão da literatura americana dos anos 90. Educação Matemática em Revista, Abril de 2002. p. $17-28$.

UFSCAR. Projeto pedagógico do curso de pedagogia da universidade federal de São Carlos. Disponível em: <www.prograd.ufscar.br/projetoped/projeto_pedagogia. pdf>. Acesso em: maio de 2007.

UNESP. Disciplinas do curso de pedagogia, campus Araraquara. Disponível em: <www.fclar.unesp.br/gradped/estruturapedag.pdf>. Acesso em: maio de 2007.

UNESP. Disciplinas do curso de pedagogia, campus Presidente Prudente. Disponível em: <www.prudente.unesp.br/ped/gradenoturno.php>. Acesso em: maio de 2007.

UNESP. Disciplinas do curso de pedagogia, campus Rio Claro. Disponível em: <www.rc.unesp.br/ib/grad/pedagogia/PED_ESTRU.htm>. Acesso em: maio de 2007.

UNESP. Disciplinas do curso de pedagogia, campus Bauru. Disponível em: <www.fc.unesp.br>. Acesso em: maio de 2007.

UNICAMP. Disciplinas do curso de pedagogia, campus de Campinas. Disponível em: <www.fe.unicamp.br/ensino/graduacao/pedagogia-curri_pedagoementas.html.>. Acesso em: maio de 2007.

USP. Disciplinas do curso de pedagogia, campus Ribeirão Preto. Disponível em: <www.ffclrp.usp.br/disciplinas/pedagogia-inicioem2005/>. Acesso em: maio de 2007.

Enviado em: 05/09

Aceito em: 10/09

308 Olhar de professor, Ponta Grossa, 12(2): 287-308, 2009

Disponível em <http://www.uepg.br/olhardeprofessor> 